\title{
Sperm characteristics in a sample of healthy adolescents in São Paulo, Brazil
}

\author{
Características de espermatozóides de um grupo \\ de adolescentes saudáveis em São Paulo, Brasil
}

${ }^{1}$ Departamento de Cirurgia, Escola Paulista de Medicina, Universidade Federal de São Paulo. Rua Leandro Dupret 204, Conj. 43, São Paulo, SP 04025-010, Brasil.

mmmsp@attglobal.net 2 Departamento de Epidemiologia e Métodos Quantitativos em Saúde, Escola Nacional de Saúde Pública, Fundação Oswaldo Cruz.

Rua Leopoldo Bulhões 1480, Rio de Janeiro, $R J$ 21041-210, Brazil. koifman@ensp.fiocruz.br

\begin{abstract}
The article presents preliminary data from a prospective investigation in a sample of healthy 14-17-year-old students from a technical school in Sao Paulo, Brazil. Ninety-six Tanner stage 5 and thirty-one Tanner stage 4 adolescents were evaluated: testicular volume was measured using a Prader orchidometer, and semen analysis was performed according to standard procedures. Median testicular volume was 20.0ml among Tanner 5 students and 15.0ml in Tanner 4 students in both the right and left testes. No significant differences were found in sperm volume or motility. Median concentration was 66.0 million/ml for Tanner 5 and 47.0 million/ml for Tanner 4 subjects. Morphological patterns showed abnormal forms in 81.9\% of Tanner 5 and 93.6\% of Tanner 4 adolescents. Oligospermia (sperm concentration $<5$ million/ml) was observed in 7.3\% of Tanner stage 5 and 12.9\% of Tanner stage 4 individuals. Azoospermia was observed in 3 students (1.8\%), with counts less than 1.0 in 8 students (4.8\%). The authors discuss the observed results, analyzing the potential implications arising from biological development and potential environmental exposures.
\end{abstract}

Key words Spermatozoa; Sperm Count; Infertility; Endocrine Disruptors

Resumo O artigo apresenta dados preliminares de um estudo prospectivo com uma amostra de alunos saudáveis variando de idade entre 14 e 17 anos, de uma escola técnica em São Paulo. Foram avaliados 96 adolescentes estágio Tanner 5 e 31 estágio Tanner 4: o volume testicular foi medido utilizando um orquidômetro de Prader, e o espermograma foi realizado de acordo com os procedimentos padronizados. O volume testicular mediano, tanto direito quanto esquerdo, era 20,0ml nos alunos Tanner 5 e 15,0ml nos alunos Tanner 4. Não foram constatadas diferenças significativas no volume ou motilidade espermática. A concentração mediana era 66,0 milhões $/ \mathrm{ml}$ para Tanner 5 e 47,0 milhões/ml para Tanner 4. Os padrões morfológicos evidenciaram formas anormais em 81,9\% dos adolescentes Tanner 5 e 93,6\% dos Tanner 4. A oligospermia (concentração espermática < 5 milhões $/ \mathrm{ml}$ ) foi observada em 7,3\% dos indivíduos Tanner 5 e 12,9\% dos Tanner 4. A azoospermia foi observada em 3 alunos (1,8\%), além de uma contagem abaixo de 1,0 em 8 alunos (4,8\%). Os autores discutem os resultados observados, analisando as implicações para o desenvolvimento biológico a partir de possíveis exposições ambientais.

Palavras-chave Espermatozóides; Contagem de Espermatozóides; Infertilidade; Desreguladores Endócrinos 


\section{Introduction}

Modification in sperm characteristics, including counting, motility and morphologic disturbances has been reported by several authors during the last decades. These changes have indeed been speculated to be associated to sex ratio and other reproductive changes also observed in several industrialized countries (Carlsen et al., 1992, 1993; Chia, 2000).

An example of such link is the exposure to certain environmental chemicals as di-bromochloro-propane used as a pesticide, which revealed a direct effect on sperm counting, inducing oligospermia and even azoospermia in exposed workers (Goldsmith et al., 1997; Potashnik \& Porath, 1995; Teitelbaum, 1999). On a whole, the association between several environmentally-linked chemical exposures and a large spectrum of reproductive changes has raised the question if the observed changes show cause-effect relationships (Cooper \& Kavlock, 1997; Irvine, 2000; Joffe, 2001; Lahdetie, 1995).

Despite the interest triggered on this topic, research on the evaluation of sperm parameters during adolescence is relatively scarce, with some contributions on the effects of environmental exposures at this age group (Abell et al., 2000; Moorman et al., 2000; Slutsky et al., 1999). However, considering the current scientific knowledge, there are no evidence fully supporting the statement that abnormal sperm parameters observed among adolescents are causally associated to environmental exposures, needing such a hypothesis to be further investigated.

Since 1998, we have been carrying out a prospective study and collecting clinical data and biological samples (sperm) among teenager students attending a technical high school in São Paulo. In this short communication, we present preliminary data on the sperm characteristics in a sample of healthy adolescents participating in the aforementioned study.

\section{Methods}

A prospective study has been carried out among male students 14-20 yr. old attending a technical high school in the State of São Paulo. A databank has been organized since 1999 with periodic physical examinations and sperm evaluations carried out with two seminal samples provided by voluntary student participants, whenever masturbation started being reported.
Students presenting systemic or endocrine diseases, genetic syndromes and genital birth defects, cryptorchidism, orchitis, scrotum surgery antecedents, or other genital diseases, such as varicocele grades 2 or 3 , and sexually transmitted diseases, were not included in the current analysis. Personal data obtained by physical examination, including those relative to genital inspection (Tanner stage classification) were recorded by a personal questionnaire, and the testicular volume was measured by using Prader orchidometer.

Seminal evaluation was ascertained at the Human Reproduction Laboratory, Federal University of São Paulo for all samples provided by voluntary students between December 1998 and March 2001. We present data on either right or left testicular volume, Tanner index of sexual maturation, volume, motility, morphology according to Kruger criteria and sperm concentration from 127 students $14-17 \mathrm{yr}$. who reported an abstinence interval ranging from 3 to 5 days.

This study was approved by the Ethical Committee of the Federal University of São Paulo, and a signed agreement was obtained from all participants and respective parents.

\section{Results}

According to the Tanner index of sexual maturation, the studied sample included 96 Tanner stage 5 and 31 Tanner stage 4 adolescents, both groups displaying similar age means (15.8 yr. and standard deviations, respectively 0.6 and 0.7 yr.) and ethnicity distribution, respectively, 82.3 and $83.9 \%$ of whites. Pearson's correlation coefficient between right and left testicular volume among Tanner stage 5 adolescents was $\mathrm{r}=0.94$ (95\%CI: 0.91-0.96) and determination coefficient $\mathrm{r}^{2}=0.88$. Among Tanner stage 4 , they were, respectively, $\mathrm{r}=0.96$ (95\%CI: 0.920.98 ) and $\mathrm{r}^{2}=0.92$.

Testicular and sperm parameters distribution in both groups are presented at Table 1 (preliminary analysis revealed that similar parameters were observed for the included students without varicocele and those presenting varicocele grade 1). Similar medians are observed for left and right testicular volumes within each Tanner stratum. Quite similar medians were also observed for sperm volumes and motility in the studied strata, respectively, $2.1 \mathrm{ml}$ and $63 \%$ among Tanner stage 5 group, versus $2.3 \mathrm{ml}$ and $62 \%$ in Tanner stage 4 adolescents.

Observed median sperm concentration was $40 \%$ higher in Tanner stage 5 strata (66.0 vs. 
47.0 millions $/ \mathrm{ml}$ in Tanner 4), likewise sperm counting, $121 \%$ higher in the former (150.0 vs. 67.8 million/ejaculate).

Abnormal sperm parameters in both groups are displayed at Table 2, all of them presented in higher proportions among Tanner stage 4 comparatively to Tanner stage 5 adolescents: motility lower than $50 \%$ was seen, respectively in $25.8 \%$ vs. $17.7 \%$; concentration lower than 20 millions $/ \mathrm{ml}, 29.0 \%$ vs. $22.9 \%$; altered morphologic scale (lower than $14 \%$ ), $93.6 \%$ vs. $81.9 \%$. All these differences were statistically no significant, except the distribution of morphologic scale lower than $4 \%$ (29.0\% among Tanner stage 4 and $12.8 \%$ in Tanner stage $5, \mathrm{p}<0.05)$. Azoospermia was observed in 3 students (1.8\%), and lower than 1.0 in 8 students $(4.8 \%)$.

\section{Discussion}

Sperm parameter evaluation among adolescents is usually complex since spermatogenesis is starting, and changes on sperm characteristics at this age can be transitory. Moreover, many adolescents have not started masturbation, and any analysis on those who did it may not be representative of the male adolescent universe. However, observed changes on sperm parameters need to be followed since they may implicate on future fertility disturbances.

The analysis of the Tanner index of sexual maturation based on the physical characteristics (testis volume, penis size according to scrotum size, pubic hair distribution) revealed that the large majority of participants were classed as adults (stages 4 and 5) and only $3 \%$ displayed a childhood degree, whose data are not presented.

The studied sample is composed, so far, by healthy individuals, being excluded all those with any pathologic antecedents, including varicocele grades 2 or 3 and sexually transmitted diseases; in addition, all of them have also reported abstinence during 3 to 5 days before sperm collection. Both restrain conditions strengthen data comparability, limiting misinterpretation introduced by related causes of abnormalities on the distribution of sperm parameters. Moreover, varicocele grade 1 is not currently envisaged as a pathological condition, just gathering scientific interest whether it could precede further development of pathological grades 2 and 3.

From a morphologic point of view, the highly observed correlation between both testis volume ( $r=0.94$ among Tanner stage 5 and $r=0.96$ among Tanner stage 4 students) can be consid-

\begin{tabular}{|c|c|c|c|}
\hline \multicolumn{4}{|c|}{$\begin{array}{l}\text { Distribution of testis volume and sperm parameters according to Tanner stage } \\
\text { classification. São Paulo adolescents sample, Brazil, 1998-2001. }\end{array}$} \\
\hline Variable & Q1 & Median & Q3 \\
\hline \multicolumn{4}{|c|}{ Left testis volume (ml) } \\
\hline Tanner stage 4 & 14.0 & 15.0 & 20.0 \\
\hline Tanner stage 5 & 15.0 & 20.0 & 25.0 \\
\hline \multicolumn{4}{|c|}{ Right testis volume (ml) } \\
\hline Tanner stage 4 & 15.0 & 15.0 & 22.0 \\
\hline Tanner stage 5 & 17.0 & 20.0 & 25.0 \\
\hline \multicolumn{4}{|l|}{ Sperm } \\
\hline \multicolumn{4}{|l|}{ Volume (ml) } \\
\hline Tanner stage 4 & 1.3 & 2.3 & 2.5 \\
\hline Tanner stage 5 & 1.5 & 2.1 & 3.0 \\
\hline \multicolumn{4}{|l|}{ Motility (\%) } \\
\hline Tanner stage 4 & 48.0 & 62.0 & 69.0 \\
\hline Tanner stage 5 & 55.0 & 63.0 & 72.0 \\
\hline \multicolumn{4}{|c|}{ Concentration (millions/ml) } \\
\hline Tanner stage 4 & 11.4 & 47.0 & 87.0 \\
\hline Tanner stage 5 & 23.8 & 66.0 & 126.3 \\
\hline \multicolumn{4}{|c|}{ Counting (millions/ejaculate) } \\
\hline Tanner stage 4 & 17.3 & 67.8 & 186.4 \\
\hline Tanner stage 5 & 41.6 & 150.0 & 273.0 \\
\hline
\end{tabular}

Q1 = First quartile; Q3 = Third quartile

Tanner $4=31$ adolescents; Tanner $5=96$ adolescents

ered indicative of individual testicular equivalence, and so far, expected anatomical equivalence. On the other hand, the statistically significant differences observed on the mean testicular volumes between Tanner stage 5 and stage 4 adolescents, respectively, 19.8ml (95\% CI: $11.2-28.4)$ vs. $16.8 \mathrm{ml}$ (95\%CI: $8.2-25.4)$ in the left testis ( $\mathrm{p}<0.000001)$, and $20.4 \mathrm{ml}(95 \%$ CI: $12.4-28.4)$ vs. $17.6 \mathrm{ml}$ (95\%CI: $8.8-26.4)$ in the right testis ( $\mathrm{p}<0.000001)$, seems to highlight the clinical heterogeneity among both clinical stages.

Observed testicular volume mean among Tanner stage 5 healthy adolescents in São Paulo (19.8ml, 95\%CI: 11.2-28.4) was comparable with data from Dutch adolescents with varicocele (mean 20.9ml, 95\%CI: 18.5-23.4; Haans et al., 1991), and lower than those observed among Dutch adolescents without varicocele (Laven et al., 1992), who showed a mean of $24.5 \mathrm{ml}$ (95\%CI: 22.7-26.4).

As a whole, the average sperm parameters observed with the studied sample (Table 1) are in agreement with the literature. Nevertheless, the distribution of some abnormality indica- 
Table 2

Abnormal sperm parameters according to Tanner stage classification.

São Paulo adolescents sample, Brazil, 1998-2001.

\begin{tabular}{|c|c|c|c|}
\hline Sperm parameter & $\mathbf{n}$ & $\%$ & $95 \% \mathrm{Cl}$ \\
\hline \multicolumn{4}{|l|}{ Motility (< 50\%) } \\
\hline Tanner stage 4 & 8 & 25.8 & $17.4-36.9$ \\
\hline Tanner stage 5 & 17 & 17.7 & $14.3-21.9$ \\
\hline \multicolumn{4}{|l|}{ Concentration } \\
\hline \multicolumn{4}{|l|}{$<20$ million/ml } \\
\hline Tanner stage 4 & 9 & 29.0 & $19.6-41.5$ \\
\hline Tanner stage 5 & 22 & 22.9 & $18.5-28.4$ \\
\hline \multicolumn{4}{|l|}{$<5$ million $/ \mathrm{ml}$} \\
\hline Tanner stage 4 & 4 & 12.9 & $8.7-18.4$ \\
\hline Tanner stage 5 & 7 & 7.3 & $5.9-9.1$ \\
\hline \multicolumn{4}{|l|}{ Morphology } \\
\hline \multicolumn{4}{|l|}{$<14 \%$} \\
\hline Tanner stage 4 & 29 & 93.6 & $63.2-100.0$ \\
\hline Tanner stage $5^{\star}$ & 77 & 81.9 & $66.3-100.0$ \\
\hline \multicolumn{4}{|l|}{$4-13 \%$} \\
\hline Tanner stage 4 & 20 & 64.5 & $43.5-92.2$ \\
\hline Tanner stage $5^{\star}$ & 65 & 69.2 & $56.0-85.8$ \\
\hline \multicolumn{4}{|l|}{$<4 \% \star \star$} \\
\hline Tanner stage 4 & 9 & 29.0 & $19.6-41.5$ \\
\hline Tanner stage $5^{\star}$ & 12 & 12.8 & $10.4-15.9$ \\
\hline
\end{tabular}

Tanner stage $4=31$ adolescents; Tanner stage $5=96$ adolescents

* Data on 94 adolescents (Tanner stage 5 )

** $p=0.036$ entific knowledge gap, it is worth mentioning the observed differences on the median sperm distribution fitting Kruger's intermediate group among Tanner stage 5 and stage 4 students, respectively, $69.2 \%$ (95\%CI: $56.0-85.8$ ) vs. $64.5 \%$ (95\%CI: 43.5-92.2).

Nevertheless, a discrepancy between World Health Organization guidelines and Kruger criteria to evaluate sperm morphology remains (Davis \& Gravance, 1994), mainly involving the latter's ability in overestimating teratozoospermic individuals. Hence, the observed results according to sperm morphologic distribution in the São Paulo sample $(29.0 \%$ among Tanner stage 4 and $12.8 \%$ among Tanner stage 5 students) may just reflect the used methodological approach.

A marked difference on the distribution of sperm production was observed between Tanner stages 5 and 4 students, with a median sperm counting of 150 millions/ejaculate in the former vs. 67.8 millions/ejaculate in the latter. Moreover, in the analyzed sample of São Paulo students, $7.3 \%$ of Tanner stage 5 and $12.9 \%$ of Tanner stage 4 showed results indicating severe oligospermia (concentration lower than 5 millions $/ \mathrm{ml}$ ) and $1.8 \%$ azoospermia. From a clinical approach, both conditions indicate the search of genetic alterations, taking into account that micro deletion at $\mathrm{Y}$ chromosome may be associated.

Mumps antecedents were obtained by interview, but taking into account the relatively low proportion of severe testis disturbances during childhood, it seems improbable to explain the large proportion of observed severe changes. The same could be said according to other explanations such as varicocele, or sexually transmitted diseases distribution in this sample - both excluded conditions -, and silent urinary infections. Therefore, the search of other environmental exposures should be investigated.

Selevan et al. (2000) compared sperm parameters from $18 \mathrm{yr}$. adolescents living in two areas presenting different levels of air pollution in the Czech Republic. The authors observed that both samples presented similar counting, but differences on sperm concentration. In the Czech polluted area, a sperm counting of 113.3 millions (150.0 millions/ejaculate among Tanner stage 5 students in Sao Paulo, also an air polluted area in Brazil) and sperm concentration of 61.2 millions/ml (66.0 in Sao Paulo) were observed.

The studied participants in this investigation used to attend classes at a technical high school during variable time periods no longer 
than two years, in which they have been, as students, probably exposed in some degree to certain chemicals (chemistry classes) and to non-ionizing radiation (computing classes).

Therefore, at least two main questions to be answered in the future arise from the observed results, both related to the sperm parameters alterations which were presented in this study. The first addresses the reasons for the observed sperm changes, and if they could result from: transient modifications inherent to the starting reproductive age, in which such sperm parameters will perhaps further normalize following reproductive maturity; environmental exposures in a broad sense, such as those consequent to air pollution, chemicals and others affecting the general population as a whole in the municipality of São Paulo; or those related to a more specific environment such as the technical school set in which participants were recruited.

The second one addresses the external validity of the these results, i.e., whether the observed sperm changes are representative of current distribution of sperm parameters in the universe of São Paulo adolescents.

Both questions remain unanswered, and future research aims to target the scope of possible involved environmental exposures associated to such observations.

\section{Conclusions}

This study on sperm parameters from a sample of 14-17 yr. healthy students in São Paulo, Brazil, revealed that Tanner stage 5 adolescents, comparatively to those classified as Tanner stage 4 , presented higher median distributions for testicular volume $(20.0 \mathrm{ml}$ vs. $15.0 \mathrm{ml})$, sperm concentration (66.0 vs. 47.0 millions $/ \mathrm{ml}$ ) and sperm counting (150.0 vs. 67.8 millions/ ejaculate). Oligospermia (sperm concentration lower than 5 millions $/ \mathrm{ml}$ ) was seen in $7.3 \%$ of Tanner stage 5 students ( $12.9 \%$ of Tanner stage 4$)$, while azoospermia was observed in 3 of the whole students sample (1.8\%).

\section{Acknowledgements}

The authors acknowledge the kind collaboration of Dr. Alejandro Oliva, Italian University Institute Hospital in Rosario, Argentina, who gently cooperated with text review and suggestions.

\section{References}

ABELL, A.; ERNST, E. \& BONDE, J. P., 2000. Semen quality and sexual hormones in greenhouse workers. Scandinavian Journal of Work, Environment \& Health, 26:492-500.

CARLSEN, E.; GIWERCKMAN, A.; KEIDING, N. \& SKAKKEBAEK, N. E., 1992. Evidence for decreasing quality of semen during past 50 years. $B M J$, 305:609-613.

CARLSEN, E.; GIWERCKMAN, A.; KEIDING, N. \& SKAKKEBAEK, N. E., 1993. Evidence for increasing incidence for abnormalities in the human testis: A review. Environmental Health Perspectives, 101(Sup. 2):65-71.

CHIA, S. E., 2000. Endocrine disruptors and male reproductive function-a short review. International Journal of Andrology, 23(Sup. 2):45-46.

COOPER, R. L. \& KAVLOCK, R. J., 1997. Endocrine disruptors and reproductive development: A weightof-evidence overview. Journal of Endocrinology, 152:159-166. 
DAVIS, R. O. \& GRAVANCE, C. G., 1994. Consistency of sperm morphology classification methods. Journal of Andrology, 15:83-91.

FIGUEIREDO, H.; TAVARES, A.; FERRAS, L.; COUCEIRO, A. \& CHAVES, I., 1996. Isolated teratozoospermia and in vitro fertilization. Journal of Assisted Reproduction and Genetics, 13:64-68.

GOLDSMITH, J. R., 1997. Dibromochloropropane: Epidemiological findings and current questions. Annals of the New York Academy of Sciences, 837:300-306.

HAANS, L. C.; LAVEN, J. S.; MALI, W. P.; te VELDE, E. R. \&WENSING, C. J., 1991. Testis volumes, semen quality and hormonal patterns in adolescents with and without varicocele. Fertility and Sterility, 56:731-736.

IRVINE, D. S., 2000. Male reproductive health: Cause for concern? Andrologia, 32:195-208.

JOFFE, M., 2001. Are problems with male reproductive health caused by endocrine disruption? Occupational and Environmental Medicine, 58:281288.

KRAUSE, W., 1993. The significance of the "routine spermiogram". A critical analysis. Hautarzt, 44: 269-274.

LAHDETIE, J., 1995. Occupation-and exposure-related studies on human sperm. Journal of Occupational and Environmental Medicine, 37:922-930.

LAVEN, J. S.; HAANS, L. C.; MALI, W. P.; te WELDE, E. R.; WENSING, C. J. \& EIMERS, J. M., 1992. Effects of varicocele treatment in adolescents: A randomized study. Fertility and Sterility, 58:756-762.
MOORMAN, W. J.; CHEEVER, K. L.; SKAGGS, S. R.; CLARK, J. C.; TURNER, T. W.; MARLOW, K. L. \& SCHRADER, S. M., 2000. Male adolescent exposure to endocrine-disrupting pesticides: Vinclozin exposure in peripubertal rabbits. Andrologia, 32: 285-293.

PARIS, E.; MENCHETTI, A.; DE LAZZARO, L.; MAROCCO, M.; NUZZO, C. \& RADICIONI, A., 1998. Lo spermiogramma nell'adolescenza. $M i$ nerva Pediatrica, 50:303.

POTASHNIK, G. \& PORATH, A., 1995. Dibromochloropropane (DBCP): A 17-year reassessment of testicular function and reproductive performance. Journal of Occupational and Environmental Medicine, 37:1287-1292.

SELEVAN, S. G.; BORKOVEC, L.; SLOTT, V. L.; ZUDOVA, Z.; RUBES, J.; EVENSON, D. P. \& PERREAULT, S. D., 2000. Semen quality and reproductive health of young Czech men exposed to seasonal air pollution. Environmental Health Perspectives, 108:887-894.

SLUTSKY, M.; LEVIN, J. L. \& LEVY, B. S., 1999. Azoospermia and oligospermia among a large cohort of DBCP applicators in 12 countries. International Journal of Occupational and Environmental Health, 5:116-122.

TEITELBAUM, D. T., 1999. The toxicology of 1,2-dibromo-3-chloropropane (DBCP): A brief review. International Journal of Occupational and Environmental Health, 5:122-126.

Submitted on 27 August 2001

Final version resubmitted on 4 December 2001

Approved on 21 December 2001 